JOURNALSCAN

Please visit the Heart website (www.heartjnl.com) for links to these articles-many to full text.

IQBAL MALIK

Editor, JournalScan

\section{ISCHAEMIC HEART DISEASE}

Clopidogrel for all acute coronary syndromes? JournalScan mentioned the CURE trial when it was presented at the American College of Cardiology meeting earlier this year (Heart $2001 ; 86: 15)$. The full paper is now published. Clopidogrel in addition to aspirin reduces the risk of death/myocardial infarction (MI) and stroke by $20 \%$ if given to all patients with non-ST elevation acute coronary syndromes. At present, clopidogrel is only used after stent implantation in the UK. The CURE study showed similar benefits in low, medium, and higher risk patients (such as those with ST depression, positive troponins, or haemodynamic instability). Initiating treatment in all patients with acute coronary syndromes awaiting transfer for in-patient angiography is probably merited. The CURE investigators suggest that this group has a $28 \%$ reduction in death/MI at nine months follow up, having had six days pretreatment with the drug.

1 CURE Investigators. Effects of clopidogrel in addition to aspirin in patients with acute coronary syndromes without ST segment elevation. The clopidogrel in unstable angina to prevent recurrent events trial investigators. N Engl J Med 2001;345:494-502.

2 Mehta SR, Yusuf S, Peters RJG, Bertrand ME, Lewis BS, Natarajan MK, Malmberg K, Rupprecht H-J, Zhao F, Chrolavicius S, Copland I, Fox KAA, for the Clopidogrel in Angina to Prevent Recurrent Events Trial (CURE) Investigators. Effects of pretreatment with clopidogrel and aspirin followed by long-term therapy in patients undergoing percutaneous coronary intervention: the PCI-CURE study. Lancet 2001;358:527-33.

In-hospital arrest has a survival rate of $23 \%$ to discharge: A study of in-hospital resuscitation events suggests that $104(23 \%)$ of 445 patients who received full advanced cardiac life support survived to hospital discharge. Survival was highest for patients with primary cardiac disease $(30 \%)$, followed by those with infectious diseases $(15 \%)$, with only $8 \%$ of patients with end stage diseases surviving to hospital discharge. Neither sex nor age affected survival. As expected, longer resuscitations were associated with poor survival. Patients who experienced arrests on a nursing unit or intensive care unit had better survival rates than those in other hospital locations. Survival for witnessed arrests (25\%) was significantly better than for non-witnessed arrests (7\%) $(p=0.005)$. Non-witnessed arrests in unmonitored beds were uniformly fatal.

3 Dumot JA, Burval DJ, Sprung J, Waters JH, Mraovic B, Karafa MT, Mascha EJ, Bourke DL. Outcome of adult cardiopulmonary resuscitations at a tertiary referral center including results of "limited" resuscitations. Arch Intern Med 2001;161:1751-8.

TMR - a placebo effect: There are no objective data to suggest sustained benefit from transmyocardial laser revascularisation (TMR). This paper evaluates 98 patients who underwent TMR versus 99 on continued medical treatment for refractory angina. The study was not blinded and there was a $60 \%$ crossover from medical to laser therapy! Not surprisingly the TMR group did better with a $44 \%$ reduction in angina versus $21 \%$ in the medical group. There was no objective evaluation of exercise time, perfusion, etc and the trial was not powered to detect mortality differences. This could all be placebo effect detected by their sensitive health questionnaires.

4 Spertus JA, Jones PG, Coen M, Garg M, Bliven B, O'Keefe J, March RJ, Horvath $\mathrm{K}$. Transmyocardial $\mathrm{CO}_{2}$ laser revascularization improves symptoms, function, and quality of life: 12-month results from a randomized controlled trial. Am J Med 2001;111:341-8.
Total cholesterol:HDL ratio is a better measure of risk than total or LDL cholesterol alone: Populations with lower cholesterol concentrations than the US and UK populations may not reach the threshold targets set by the European Society of Cardiology and American Heart Association/American College of Cardiology guidelines for initiation of statin treatment, but may still be at risk. The same is true of diabetics in the UK, with a low high density lipoprotein (HDL) concentration compounding the cholesterol risk. In a case-control study of Algerian men with MI compared to controls, the total cholesterol (TC):HDL ratio predicted risk better than TC alone. Algerian patients have a TC of $5.2 \mathrm{mmol} / \mathrm{l}$ versus $5.8 \mathrm{mmol} / \mathrm{l}$ in France and $6.2 \mathrm{mmol} / \mathrm{l}$ in Ireland. The ratio of TC:HDL remained at about 6 for patients with MI from all countries while controls had a ratio of 5.0 or less.

5 Mediene-Benchekor S, Brousseau T, Richard F, Benhamamouch S, Amouyel P, and ECTIM Study Group. Blood lipid concentrations and risk of myocardial infarction. Lancet 2001;358:1064-5.

BNP as a risk stratifier in ACS: Brain (B type) natriuretic peptide (BNP) is a neurohormone synthesised predominantly in ventricular myocardium. It provides independent prognostic information in patients with transmural myocardial infarction and can help screen for HF. This trial measured BNP in plasma specimens obtained a mean (SD) of 40 (20) hours after the onset of ischaemic symptoms in 2525 patients from the orbofiban in patients with unstable coronary syndromes-thrombolysis in myocardial infarction 16 study (OPUS-TIMI 16). The baseline level of BNP was correlated with the risk of death, heart failure, and MI at 30 days and 10 months in subgroups of patients who had myocardial infarction with ST segment elevation $(p=0.02)$, patients who had myocardial infarction without ST segment elevation $(p<0.001)$, and patients who had unstable angina $(p<0.001)$. After adjustment for independent predictors of the long term risk of death, the odds ratios for death at 10 months in the second, third, and fourth quartiles of BNP were 3.8 (95\% confidence interval (CI) 1.1 to 13.3 ), 4.0 (95\% CI 1.2 to 13.7 ), and 5.8 (95\% CI 1.7 to 19.7). The concentration of BNP was also associated with the risk of new or recurrent myocardial infarction $(p=0.01)$ and new or worsening heart failure $(p<0.001)$ at 10 months. Cut off of $80 \mathrm{pg} / \mathrm{ml}$ was suggested as a concentration above which risk was substantially increased. Risk prediction was independent of troponins and $\mathrm{C}$ reactive protein.

6 de Lemos JA, Morrow DA, Bentley JH, Omland T, Sabatine MS, McCabe $\mathrm{CH}$, Hall C, Cannon CP, Braunwald E. The prognostic value of B-type natriuretic peptide in patients with acute coronary syndromes. $N$ Engl $J$ Med 2001;345:1014-21.

ST analysis of Holter monitors is not a poor man's exercise test: Asymptomatic ischaemia is known to be associated with worse outcome, and can be diagnosed on ST segment analysis of Holter monitors. This study prospectively assessed 277 patients with chest pain referred for coronary angiography. All patients had a 24 hour ambulatory Holter within 72 hours of the angiogram and were then followed up for the occurrence of death, infarction, hospitalisation for unstable angina, and the need for revascularisation over a five year period. The overall incidence of coronary artery disease was high, at $80 \%$, yet only $20 \%$ of patients had significant ST segment deviation on ambulatory monitoring. Comparing patients with and without ST segment changes who were otherwise matched, the incidence of coronary artery disease (CAD) at angiography was similar in the two groups $(90 \%$ and $79 \%$, respectively) and the occurrence of the combined clinical end point was also similar ( $48 \% v 44 \%)$. Overall, the sensitivity of Holter ST segment deviation for diagnosing CAD was only $19 \%$ with a specificity of $91 \%$, making its diagnostic accuracy very poor, even among patients with left main stem or triple vessel disease. This study was flawed as the patients were already at high risk for $\mathrm{CAD}$ and may have been limiting their activity to reduce 
angina episodes. This was the wrong population for this test, in addition to it being the wrong test.

7 Nair CK, Khan IA, Esterbrooks DJ, Ryschon KL, Hilleman DE. Diagnostic and prognostic value of Holter-detected ST-segment deviation in unselected patients with chest pain referred for coronary angiography: a long-term follow-up analysis. Chest 2001;120:834-9.

Angiography for patients $>75$ with resistant angina: Patients older than 75 years are often denied access to coronary angiography. Now the TIME study addresses this issue by randomising to medical treatment or angiography after two drugs have been tried to relieve symptoms. Of 153 patients in the invasive group, $109(74 \%)$ underwent revascularisation. The remaining $38(26 \%)$ were treated medically because they could not be revascularised (19), because they refused revascularisation (7), or had no significant coronary artery disease (11). Coronary artery bypass graft (CABG) surgery was performed in $25(20 \%)$, and 68 $(54 \%)$ had percutaneous coronary intervention (PCI) using at least one stent. In the optimum medical group, anti-anginal medication was increased by a mean (SD) of $0.80(0.6)$ drugs per patient, with additional increases in drug dosages in $81(55 \%)$ patients. Death, non-fatal MI, or hospital admission for acute coronary syndrome occurred in $49 \%$ of the medical group and in $19 \%$ of the invasive group $(p<0.0001)$. Mortality at six months did not differ between the two groups $(8.4 \%$ in the invasive group, $4.1 \%$ in the medical group), but the study was not powered to detect such a difference. A third of the patients in the medical group needed a revascularisation procedure during follow up for uncontrollable symptoms.

8 The TIME Investigators. Trial of invasive versus medical therapy in elderly patients with chronic symptomatic coronary-artery disease (TIME): a randomised trial. Lancet 2001;358:951.

LIMA and RIMA for CABG as the norm? Ten years after CABG, $90-95 \%$ of left internal mammary artery (LIMA) grafts are patent and disease free, whereas $75 \%$ of vein conduits are blocked or severely diseased. Thus, 10-15 years after their first operation, $30 \%$ of patients might need CABG to be redone, with greater risk than first time surgery. LIMA grafts attached to nonleft anterior descending (LAD) vessels also seem to do well. Seven studies of cohorts of patients with LIMA and right internal mammary artery (RIMA) grafts versus LIMA alone were analysed, with a total of 15962 patients, 4693 of whom got LIMA and RIMA. The bilateral group had significantly better survival than the single group (hazard ratio for death $0.81,95 \%$ CI 0.70 to 0.94). Exclusion of methodologically weak studies improved survival rates with bilateral internal mammary artery grafts. Total arterial grafting is increasing, but a randomised trial with angiographic follow up may be warranted, particularly as LIMA + RIMA increases sternal wound complications, especially in diabetics.

9 Taggart DP, D'Amico R, Altman DG. Effect of arterial revascularisation on survival: a systematic review of studies comparing bilateral and single internal mammary arteries. Lancet 2001;358:870-5.

Stroke after CABG is a tragedy: Previous studies have suggested $3 \%$ risk of major neurological event after CABG (including stroke). This prospective evaluation suggests that clinical stroke occurred in $3.6 \%$ of 5971 patients, being infarction in $72 \%$ of cases. The cause was embolic $(83 \%)$ or watershed infarction $(24 \%)$. Interestingly, although only $13 \%$ of these patients reported previous stroke, $42 \%$ had evidence of previous brain ischaemia on computed tomography/magnetic resonance imaging. After a stroke, survival was under $50 \%$ at five years, and two thirds had moderate or severe disability. Longer cardiopulmonary bypass time, renal impairment, longer intensive therapy unit stay, and longer wake up time were predictable indicators of survival.

10 Salazar JD, Wityk RJ, Grega MA, Borowicz LM, Doty JR, Petrofski JA, Baumgartner WA. Stroke after cardiac surgery: short- and long-term outcomes. Ann Thorac Surg 2001;72:1195-202.

Statins and the eye: Some studies in dogs suggest that statin use may increase cataract formation. A UK case-control study of 7405 cases and 28327 controls suggests statin use was not associated with an increased cataract risk (adjusted odds ratio (OR)
$0.9,95 \%$ CI 0.5 to 1.6 ), nor was use of fibrates or of other lipid lowering drugs (adjusted OR 0.5, 95\% CI 0.3 to 1.1 ; and OR 0.7 , $95 \%$ CI 0.1 to 5.6 , respectively). However, use of simvastatin and an inhibitor of its metabolism, such as erythromycin, did result in increased risk (adjusted OR 2.2, 95\% CI 1.2 to 4.1 ). In a separate study, statins seem to be associated with a reduced risk of macular degeneration (corrected OR $0.09,95 \%$ CI 0.01 to 0.73 ).

11 Schlienger RG, Haefeli WE, Jick H, Meier CR. Risk of cataract in patients treated with statins. Arch Intern Med 2001;161:2021-6.

12 Hall NF, Gale CR, Syddall H, Phillips DIW, Martyn CN. Risk of macular degeneration in users of statins: cross sectional study. BMJ 2001;323:375-6.

\section{HEART FAILURE}

Failing to deliver heart failure treatment: Previous studies suggest a prevalence of heart failure of $2.9 \%$ in those aged $<75$ years. In this study of a population aged $>45$ years, $1.7 \%$ had left ventricular systolic dysfunction. Only $50 \%$ of these had symptoms. Of those with definite heart failure, only $30 \%$ were on angiotensin converting enzyme (ACE) inhibitors and only $11 \%$ on $\beta$ blockers. Screening for disease is useful when treatment is available, but the treatment has to be prescribed (and taken) to be effective.

1 Davies MK, Hobbs FDR, Davis RC, Kenkre JE, Roalfe AK, Hare R, Wosornu D, Lancashire RJ. Prevalence of left-ventricular systolic dysfunction and heart failure in the echocardiographic Heart of England screening study: a population based study. Lancet 2001;358:439-44.

Heart failure nurses reduce admissions and thereby costs of treatment: Admissions with heart failure are common. Excluding those caused by valve disease or acute MI, 165 patients with systolic left ventricular dysfunction were randomised to standard care, or inpatient and subsequent intensive outpatient monitoring by specialised heart failure nurses, with a remit to implement evidenced based treatment. The trial was not designed to took at mortality differences, but the main cost of heart failure treatment is recurrent admission. The combined end point of death or readmission for heart failure was investigated at one year. Only 31 patients $(37 \%)$ in the intervention group died or were readmitted with heart failure compared with $45(53 \%)$ in the usual care group (hazard ratio $0.61,95 \%$ CI 0.33 to 0.96). Compared with usual care, patients in the intervention group had fewer readmissions for any reason $(86 v 114, \mathrm{p}=0.018)$, fewer admissions for heart failure $(19 v 45, \mathrm{p}<0.001)$, and spent fewer days in hospital for heart failure (mean $3.43 v 7.46$ days, $p=0.0051$ ). They also were on larger doses of ACE inhibitors.

2 Blue L, Lang E, McMurray JJV, Davie AP, McDonagh TA, Murdoch DR, Petrie MC, Connolly E, Norrie J, Round CE, Ford I, Morrison CE. Randomised controlled trial of specialist nurse intervention in heart failure. BMJ 2001;323:715-18.

Exudates caused by heart failure: Pleural effusions are common in patients with heart failure. Light's criteria for differentiation between exudates and transudates were used to classify effusions in 81 patients. A total of 54 effusions in 47 patients were found. Of these an obvious cause for the exudates (except heart failure) was found in 22 effusions in 20 patients. Intravenous diuretic treatment in the 24 hours before thoracentesis was significantly more common among patients with exudates without a specific cause.

3 Gotsman I, Fridlender Z, Meirovitz A, Dratva D, Muszkat M. The evaluation of pleural effusions in patients with heart failure. Am J Med 2001; 111:375-8.

\section{GENERAL CARDIOLOGY}

Not "economy class syndrome" but "long haul syndrome": A total of 135.29 million passengers from 145 countries or other areas arrived at Charles de Gaulle Airport during the period of one study, of whom 56 had confirmed pulmonary embolism. The 
incidence of pulmonary embolism was much higher among passengers travelling more than $5000 \mathrm{~km}$ ( 3100 miles) $(1.5$ cases per million, as compared with 0.01 case per million among those travelling less than $5000 \mathrm{~km}$ ). The incidence of pulmonary embolism was 4.8 cases per million for those travelling more than $10000 \mathrm{~km}$ (6200 miles).

1 Lapostolle F, Surget V, Borron SW, Desmaizieres M, Sordelet D, Lapandry C, Cupa M, Adnet F. Severe pulmonary embolism associated with air travel. N Engl J Med 2001;345:779-83.

5-Fluorouracil can cause coronary vasospasm: The mechanism of 5-fluorouracil (5-FU) cardiotoxicity is not certain. In vitro studies have shown an endothelium independent vasoconstriction of vascular smooth muscle cells, involving activation of protein kinase C. Previous case reports suggest very high doses $(>800 \mathrm{mg} /$ day) can cause vasospastic angina. Now there is a report of three cases likely to be vasospasm secondary to 5-FU low dose infusion. Symptoms were associated with the initiation of 5-FU treatment, and disappeared after its discontinuation. Although angiographic confirmation of vasospasm was not obtained, ST segment elevation during the early recovery phase of an exercise stress test is considered a hallmark of transmural ischaemia caused by vasospastic origin. Disappearance of these changes with repeat exercise testing after discontinuation of 5-FU treatment confirmed the likely diagnosis.

2 Lestuzzi C, Viel E, Picano E, Meneguzzo N. Coronary vasospasm as a cause of effort-related myocardial ischemia during low-dose chronic continuous infusion of 5-fluorouracil. Am J Med 2001;111:316-18.

Syncope-two thirds of patients have an easily identifiable cause: In 611 consecutive patients who presented to the emergency department with syncope as a chief complaint, initial evaluation included history and clinical examination, with carotid sinus massage, ECG, and basic laboratory testing. This yielded a suspected cause of syncope in $69 \%$ of the 611 patients, including neurocardiogenic syncope ( $\mathrm{n}=234,36 \%$ ), orthostatic hypotension $(\mathrm{n}=156,24 \%)$, arrhythmia $(\mathrm{n}=24,4 \%)$, and other diseases $(\mathrm{n}=32,5 \%)$. Extensive cardiovascular workups, which were performed in 122 of the 155 patients in whom syncope remained unexplained, provided a suspected cause of syncope in only 30 more patients, including arrhythmias in 18, all of whom had abnormal baseline ECGs. An acute coronary syndrome was the cause in only nine patients.

3 Sarasin FP, Louis-Simonet M, Carballa D, Slama S, Rajeswaran A, Metzger JT, Lovis C, Unger P-F, Junod A-F. Prospective evaluation of patients with syncope: a population-based study. Am J Med 2001; 111:177-84

The importance of renervation of the transplanted heart: Does a transplanted heart feel pain as it has no nerve supply? This paper shows that this is not true. It demonstrates partial renervation in 16 of 29 transplant patients. Renervation improves mean (SD) exercise time (6.1 (1.5) v 8.2 (1.2) minutes in the group with reinnervation, $\mathrm{p}<0.01)$ and heart rate $(121$ (13) $v 143$ (15) beats per minute, $\mathrm{p}<0.01$ ), probably by a sympathetic mediated positive ionotropic and chronotropic response.

4 Bengel FM, Ueberfuhr P, Schiepel N, Nekolla SG, Reichart B, Schwaiger $M$. Effect of sympathetic reinnervation on cardiac performance after heart transplantation. N Engl J Med 2001;345:731-8.

\section{HYPERTENSION}

Lower the BP after CVA to reduce recurrent CVA risk: Aspirin reduces recurrent cerebrovascular accident (CVA) by about $20 \%$. Lowering systolic blood pressure (BP) by $10 \mathrm{~mm} \mathrm{Hg}$ lowers recurrent CVA by $28 \%$ in patients with ischaemic CVAs or transient ischaemic attacks. Lowering diastolic BP by $5-6 \mathrm{~mm} \mathrm{Hg}$ lowers risk of first CVA by a third. Now the PROGRESS study suggests that lowering BP by $9 / 5 \mathrm{~mm} \mathrm{Hg}$ can reduce recurrent CVAs. Stroke occurred in $307(10 \%)$ individuals assigned active treatment, compared with $420(14 \%)$ assigned placebo (relative risk reduction $28 \%$ ( $95 \%$ CI $17 \%$ to $38 \%$ ) over four years follow up). Combination therapy with perindopril plus indapamide reduced $\mathrm{BP}$ by $12 / 5 \mathrm{~mm} \mathrm{Hg}$ and stroke risk by $43 \%$ (95\% CI $30 \%$ to $54 \%$ ). The reduction in first MI (38\% reduction in non-fatal MI) was in keeping with data from the HOPE trial. Most were on aspirin and half were on antihypertensives. It seems that the lower the blood pressure the better. Interestingly, perindopril alone, which produced a smaller BP drop, was not associated with significant benefit.

1 PROGRESS Collaborative Group. Randomised trial of a perindoprilbased blood-pressure-lowering regimen among 6105 individuals with previous stroke or transient ischaemic attack. Lancet 2001;358:1033-41.

\section{BASIC RESEARCH}

A case report in a science journal: Nitric oxide (NO) is known to be a vasodilator. Disease states that affect the endothelium display impaired NO dependent vasodilatation. Thus atherosclerosis is associated with abnormal flow mediated brachial artery dilatation. The authors report a rare case of lysinuric protein intolerance (LPI) - an autosomal recessive defect of dibasic amino acid transport caused by mutations in the $S L C 7 A 7$ gene, resulting in an L-arginine deficiency. They found that the patient's serum concentration of $\mathrm{NO}$ and his flow mediated brachial artery vasodilator response were each approximately $70 \%$ lower than in controls. Both of these could be corrected by intravenous infusion of L-arginine. Despite a normal coronary angiogram, exercise testing and positron emission tomography showed evidence of myocardial ischemia. Again this could be corrected by intravenous administration of L-arginine. This provides more evidence that $\mathrm{NO}$ is vital in the control of tissue perfusion.

1 Kamada Y, Nagaretani H, Tamura S, Ohama T, Maruyama T, Hiraoka H, Yamashita S, Yamada A, Kiso S, Inui Y, Ito N, Kayanoki Y, Kawata S, Matsuzawa $Y$. Vascular endothelial dysfunction resulting from L-arginine deficiency in a patient with lysinuric protein intolerance. J Clin Invest 2001;108:717-24.

An animal model for long QT syndrome type III: Abnormal prolongation of repolarisation, reflected by a long QT interval, is associated with ventricular arrhythmias in the long QT (LQT) syndrome. An inherited deletion in the cardiac sodium $\left(\mathrm{Na}^{+}\right)$ channel, encoded by $S C N 5 A$, causes the severe autosomal dominant LQT3 syndrome, associated with fatal ventricular arrhythmias. This report shows that $S c n 5 a^{A /+}$ mice lacking the same residues as LQT3 patients showed the essential features of the LQT3 syndrome and were highly susceptible to ventricular tachyarrhythmias in response to sudden heart rate accelerations or premature beats. These arrhythmias were attributable to a paradoxical lengthening of the action potential, initiated by an increased peak and late $\mathrm{Na}^{+}$inward current. Adrenergic agonists normalised the response to rate acceleration in vitro and suppressed arrhythmias upon premature stimulation in vivo. These results show the possible risk of sudden heart rate accelerations. The $\operatorname{Scn} 5 a^{A /+}$ mouse with its predisposition for pacing induced arrhythmia might be useful for the development of new treatments for the LQT3 syndrome.

2 Nuyens D, Stengl M, Dugarmaa S, Rossenbacker T, Compernolle V, Rudy Y, Smits JF, Flameng W, Clancy CE, Moons L, Vos MA, Dewerchin M, Benndorf K, Collen D, Carmeliet E, Carmeliet P. Abrupt rate accelerations or premature beats cause life-threatening arrhythmias in mice with longQT3 syndrome. Nature Med 2001:7;1021-7.

fournals scanned - American Journal of Medicine; American Journal of Physiology: Heart and Circulatory Physiology; Annals of Emergency Medicine; Annals ofy: Thoracic Surgery; Archives of Internal Medicine; BMJ; Chest; European of Thoracic Surgery; Archives of Internal Medicine; BMJ; Chest; European
Journal of Cardiothoracic Surgery; Lancet; JAMA; Journal of Clinical InvestigaJournal of Cardiothoracic Surgery; Lancet; JAMA; Journal of Clinical Investiga-
tion; Journal of Diabetes and its Complications; Journal of Immunology; Jourtion; Journal of Diabetes and its Complications; Journal of Immunology; Jour-
nal of Thoracic and Cardiovascular Surgery; Nature Medicine; New England Journal of Medicine; Pharmacoeconomics; Thorax.

Reviewers - C Baker, E Barnes, V Bhatia, R Desilva, M Earley, K Fox, D Gorog, G Jenkins, R Kaprilian, A Kapur, M Khan, P Lambiese, V Markides, M Poullis, P Ramrakha, J Strange, B Wasan, H Walker. 